\title{
The GTN patch: a simple and effective new approach to cardioprotection?
}

\author{
Derek M. Yellon ${ }^{1}$ (1) $\cdot$ Zhenhe He$^{1} \cdot$ Rayomand Khambata $^{2} \cdot$ Amrita Ahluwalia $^{2} \cdot$ Sean M. Davidson ${ }^{1}$
}

Received: 28 March 2018 / Accepted: 13 April 2018 / Published online: 17 April 2018

(c) The Author(s) 2018

\begin{abstract}
There remains a significant un-met need to reduce the extent of myocardial injury caused by ischaemia and reperfusion injury in patients experiencing an ST-elevation MI. Although nitric oxide is central to many cardioprotective strategies currently undergoing investigation, cardioprotection from the delivery of nitrates/nitrites has been inconsistently observed. The route of administration appears to be a critical variable. The glyceryl trinitrate (GTN) patch is commonly used as a simple and practical means of delivering nitric oxide to patients with ischaemic heart disease, but whether acute cardioprotection can be achieved by application of a GTN patch has not been investigated before. Here, we use a mouse model to demonstrate that a GTN patch is highly cardioprotective when applied immediately prior to $40 \mathrm{~min}$ occlusion of the left anterior coronary artery followed by $2 \mathrm{~h}$ reperfusion, reducing infarct size from $54 \pm 4 \%$ in control mice, to $28 \pm 4 \%(P<0.001, N=7)$. The degree of protection was similar to that achieved with a standard remote ischaemic preconditioning protocol. Furthermore, and of greater potential clinical relevance, a GTN patch was also protective when applied well after the initiation of ischaemia and $15 \mathrm{~min}$ prior to reperfusion ( $28 \pm 4$ vs $59 \pm 4 \% ; P<0.01, N=5)$. Confirmatory experiments verified the expected effect increase in plasma nitrite levels and decrease in blood pressure. The simplicity and rapidity of GTN patch application (easily applied in an ambulance or cardiac catheterization laboratory), and low cost (potentially relevant to low-income countries), make it attractive for further investigation.
\end{abstract}

Keywords Nitrate $\cdot$ Nitric oxide $\cdot$ Cardioprotection $\cdot$ Mouse $\cdot$ Ischaemia $\cdot$ Reperfusion

\section{Introduction}

There remains a significant un-met need to reduce the extent of myocardial injury caused by ischaemia and reperfusion injury in patients experiencing an ST-elevation MI (STEMI) $[11-13,15]$. The ideal cardioprotective modality would be simple, effective, and able to be easily and rapidly delivered by the first responder. One promising procedure that is being investigated at present is remote ischaemic preconditioning (RIPC), in which several brief episodes of ischaemia and reperfusion are applied to a limb, thereby signalling to the heart to stimulate cardioprotection. RIPC has shown promise

Derek M. Yellon

D.Yellon@ucl.ac.uk

1 The Hatter Cardiovascular Institute, University College London, 67 Chenies Mews, London WC1E 6HX, UK

2 William Harvey Research Institute, Barts and The London Medical School, Queen Mary, University of London, Charterhouse Square, London EC1M 6BQ, UK in reducing infarct size in STEMI patients in numerous proof of concept studies and is now undergoing investigation in a large, multi-centre, randomized trial [3, 14, 28]. However, the application of RIPC takes at least $30 \mathrm{~min}$. Although the precise mechanism of RIPC is still under investigation, circulating nitrite originating from RIPC limb is believed to contribute to its cardioprotection [29,36].

Organic nitrates, such as glyceryl trinitrate (GTN), are a highly effective means of rapidly delivering nitrate and nitrite into the blood stream, and are potent vasodilators. The transdermal GTN patch is widely used to reduce angina in patients with acute and chronic ischaemic syndromes due to coronary artery disease. Application of a GTN patch has been shown to induce delayed cardioprotection when applied to rabbits $72 \mathrm{~h}$ prior to infarction [19]. However, whether a GTN patch is protective when applied at a more clinically relevant time-point, such as during ischaemia, has never been investigated. We have investigated this hypothesis using an in vivo mouse model of ischaemia and reperfusion. 


\section{Materials and methods}

All animals received humane care in accordance with the United Kingdom Home Office Guide on the Operation of Animal (Scientific Procedures) Act of 1986. The investigation conforms to the guidelines from Directive 2010/63/ EU of the European Parliament on the protection of animals used for scientific purposes or the NIH guidelines. All experiments were approved by the appropriate ethics committee and have, therefore, been performed in accordance with the ethical standards laid down in the 1964 Declaration of Helsinki and its later amendments.

10- to 12 -week-old C57Bl/6 male mice were anaesthetized by i.p. injection of $80 \mathrm{mg} / \mathrm{kg}$ pentobarbitone at a concentration of $20 \mathrm{mg} / \mathrm{ml}$ in $0.9 \%$ (w/v) saline and maintained at $36.5 \pm 0.5{ }^{\circ} \mathrm{C}$ on a heating mat. Surgery was started once pedal and tail reflexes were abolished and depth of anaesthesia was monitored throughout. Mice were intubated using a $19 \mathrm{G}$ cannula and ventilated using a MiniVent, type 845, Small Animal Ventilator (Harvard Apparatus, Kent, UK), supplemented with either room air or $100 \%$ oxygen, at a flow rate of $1.0 \mathrm{l} / \mathrm{min}$ with $2 \mathrm{cmH}_{2} \mathrm{O}$ PEEP, stroke volume $200 \mu \mathrm{l}$ at 130 strokes/min. After orotracheal intubation, the left common carotid artery running parallel to the trachea was carefully dissected and isolated, taking care not to damage the vagus nerve. The artery was cannulated using a thinned tip polyethylene tube (OD $0.96 \mathrm{~mm}$ ) that was pre-filled with saline containing 10 units of heparin and was connected a calibrated pressure transducer. Mean arterial blood pressure was recorded using Labchart software.

A transdermal $5 \mathrm{mg}$ GTN patch for human use was cut into eight equal pieces, and a single piece (containing $0.6 \mathrm{mg}$ GTN) was applied to the depilated abdomen of an anaesthetized mouse. Inactive tape was applied to control mice. The change in blood pressure was measured after $10 \mathrm{~min}$. The blood was then immediately removed by cardiac puncture, directly into a syringe containing sodium citrate. Plasma was obtained by centrifugation at $13,000 \times g$ for $15 \mathrm{~min}$. Blood plasma was used for determination of total nitrate and nitrite $\left(\mathrm{NO}_{x}\right)$ concentrations using ozone chemiluminescence. Plasma was filtered using Sartorius Vivaspin 5003000 MWCO PES (Sartorius Stedim Biotech, Germany) at $4{ }^{\circ} \mathrm{C}, 14,000 \mathrm{~g}$ for $60 \mathrm{~min}$. Prior to use, filters were washed twice with low $\mathrm{NO}_{x}$ containing $18 \mathrm{M} \Omega$ $\mathrm{dH}_{2} \mathrm{O}$. An NO analyser (NOA 280A, Sievers, UK) was used to measure NO based on the gas-phase chemiluminescent reaction between NO and ozone. To determine total $\mathrm{NO}_{x}$ concentration, samples were added to the purge vessel containing $0.1 \mathrm{M}$ vanadium(III) chloride in $1 \mathrm{M}$ hydrochloric acid refluxing at $95{ }^{\circ} \mathrm{C}$ under nitrogen. Nitrite concentration was determined by addition of samples to the purge vessel containing $0.09 \mathrm{M}$ potassium iodide in glacial acetic acid under nitrogen at room temperature. Both of these conditions result in NO generation in the gas phase which is carried from the purge vessel to the NOA analyser where it reacts with ozone to emit a photon of light which is detected by the analyser. Nitrate concentration was calculated by subtraction of the nitrite concentration from the total $\mathrm{NO}_{x}[4,20]$.

In a second set of experiments, the left anterior descending (LAD) coronary artery of anaesthetized mice was occluded (verified by ST elevation, hypokinesia and pallor) for $40 \mathrm{~min}$ followed by $2 \mathrm{~h}$ reperfusion, after which infarct size was measured by tetrazolium staining and expressed as a percentage of area at risk, determined using Evan's blue. A GTN patch (1/8) or inactive tape was applied 10 min prior to ischaemia and left throughout the experiment. Remote ischaemic preconditioning (RIPC) was induced using a 6-mm lumen custom vascular occluder (Kent Scientific, CT, USA) around the right hind limb inflated to $250 \mathrm{mmHg}$ to induce three cycles of $5 \mathrm{~min}$ ischaemia followed by $5 \mathrm{~min}$ reperfusion.

In a third set of experiments, ischaemia and reperfusion was performed as described above, but the patch (1/8) was applied after $25 \mathrm{~min}$ ischaemia, $15 \mathrm{~min}$ prior to reperfusion. All mice (i.e.: both control and those receiving the GTN patch) were transfused via the jugular vein with $250 \mu \mathrm{l}$ blood from a donor mouse during reperfusion, in order to ensure blood pressure was maintained.

The results are shown as mean \pm standard deviation of the mean. Statistical comparison of the groups was made by two-way ANOVA, with Bonferroni correction for multiple comparisons. A significance value of $P<0.05$ was considered significant.

\section{Results}

In anaesthetized mice, application of the GTN patch resulted in a $13 \pm 2 \%$ decrease in mean arterial blood pressure (MAP) after $10 \min (P<0.01, N=7)$ (Fig. 1a). Plasma nitrite levels were confirmed to be $6 \pm 2$-fold greater than in mice receiving the control tape $(P<0.05, N=6-7)$ (Fig. 1b). Plasma nitrate and total nitrate + nitrite levels were similarly increased, although the difference was not significant (Fig. 1c, d).

In a second set of experiments, application of a GTN patch $10 \mathrm{~min}$ prior to $40 \mathrm{~min}$ ischaemia followed by $2 \mathrm{~h}$ reperfusion significantly reduced myocardial infarct size from $54 \pm 4$ to $28 \pm 4 \%(P<0.001, N=7)$ (Fig. 2a). The degree of protection was equivalent to a positive control consisting of a standard remote ischaemic preconditioning protocol of three cycles of 5 min hind-limb, blood-flow occlusion (Fig. 2a). It was important to verify that the GTN patch would reduce 

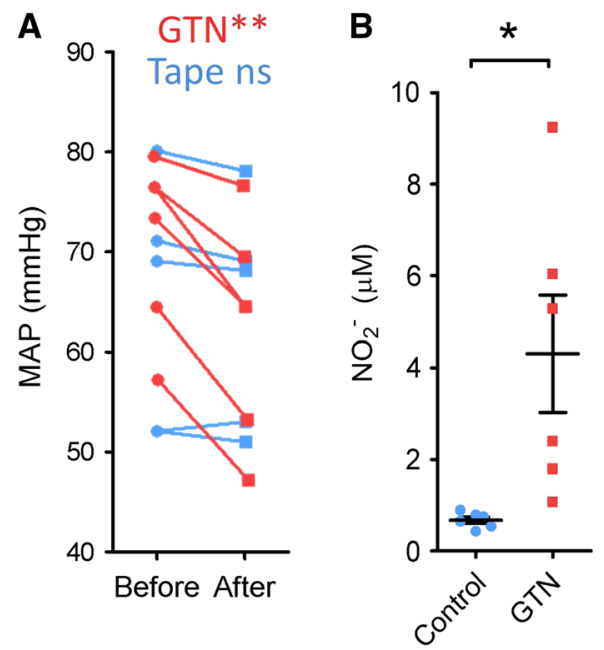

Fig. 1 a The mean arterial blood pressure of anaesthetized mice decreased significantly $10 \mathrm{~min}$ after adhesion of a GTN patch to the abdomen (red), but not after control adhesive tape (blue). $* * P<0.01$ by paired $T$ test. b-d In mice treated with a GTN patch, plasma

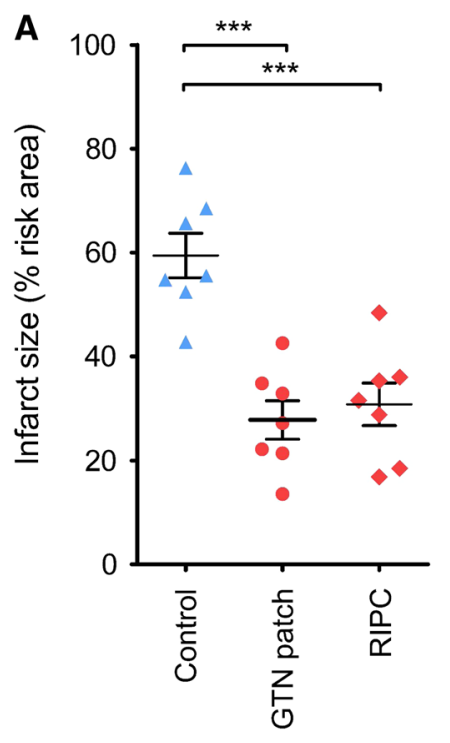

Prior to ischaemia

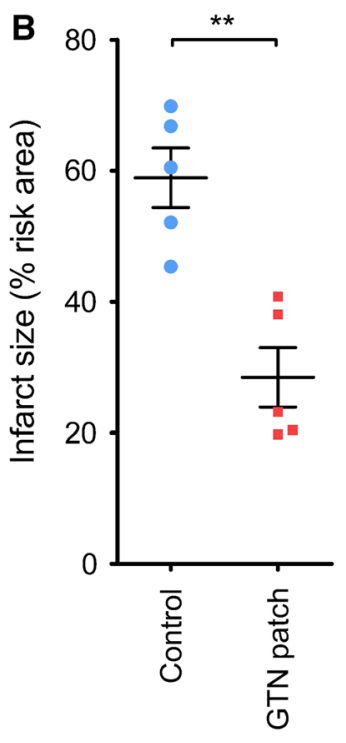

Prior to reperfusion
Fig. 2 a Infarct size as a percentage of the area at risk was significantly decreased by a GTN patch applied 10 min prior to ischaemia. A positive control of remote ischaemic preconditioning was equally protective (RIPC). b GTN patch applied 15 min prior to reperfusion was cardioprotective. $* * * P<0.001$ one-way ANOVA and Tukey post-test. $* * P<0.01$ by unpaired $T$ test

infarct size when applied prior to reperfusion, as this better reflects the potential scenario in which it would be applied to a patient in an ambulance. Application of the GTN patch $15 \mathrm{~min}$ prior to reperfusion was equally effective at reducing infarct size ( $28 \pm 4$ vs $59 \pm 4 \% ; P<0.01, N=5)$ (Fig. $2 b)$.
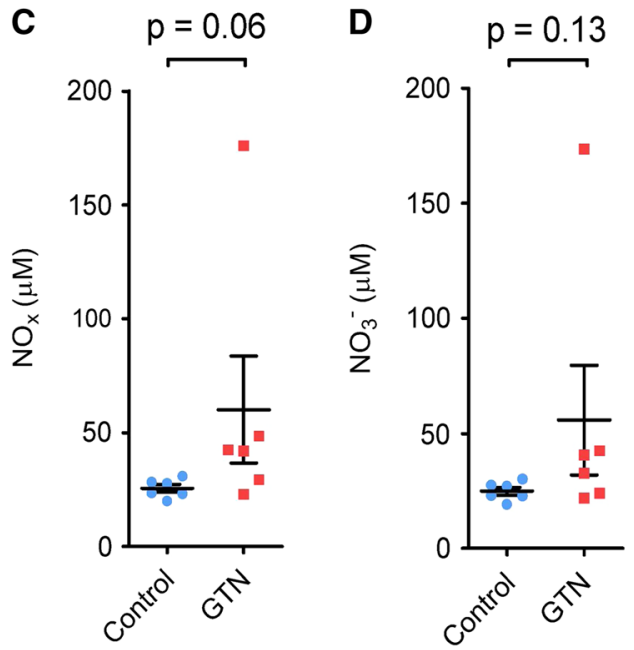

nitrite $\left(\mathrm{NO}_{2}{ }^{-}\right)$concentration was significantly elevated after $10 \mathrm{~min}$ (* $P<0.05$ by unpaired $T$ test). The difference in plasma nitrate $\left(\mathrm{NO}_{3}{ }^{-}\right)$and total nitrates and nitrites was not significant

\section{Discussion}

These results suggest that the simple application of a transdermal GTN patch may be an effective means of protecting the heart against ischaemia and reperfusion injury, whether it is applied prior to ischaemia, or prior to reperfusion. Organic nitrates such as GTN are rapidly metabolized into nitrite, which is then reduced to the active vasodilator molecule, nitric oxide. Although nitric oxide is central to many cardioprotective strategies, including remote preconditioning, cardioprotection from the delivery of nitrates/ nitrites has been inconsistently observed. The route and timing of administration appears to be a critical variable $[19,31]$. For example, i.v. infusion of sodium nitrite at the time of reperfusion did not reproducibly protect animals in the CAESAR trial, but intracoronary or oral nitrite has successfully reduced infarct size in other animal studies $[7,16,32,36]$. A recent systematic review of nitric oxide therapies given at reperfusion, which included 21 animal studies, found significant protection in the majority of studies, with a mean overall reduction in infarct size of $17.93 \%$ (95\% confidence interval: $22.05,13.81$ ) [2]. The exceptions in which no protection was observed included 5 studies: two in which $2 \mu \mathrm{g} / \mathrm{kg} / \mathrm{min}$ GTN was administered to rabbits or pigs via continuous IV infusion starting 5 or $10 \mathrm{~min}$ prior to reperfusion [25,30]; a study in rats in which $4 \mathrm{mg} / \mathrm{kg} \mathrm{NaNO}_{2}$ was administered IV starting $10 \mathrm{~s}$ after the onset of reperfusion [1]; a study from 1997 in which acidified $\mathrm{NaNO}_{2}$ was infused IV in adult male mongrel dogs starting at the time of reperfusion [37]; and a study in which inhalation of $80 \mathrm{ppm} \mathrm{NO}$ was initiated $0.5 \mathrm{~min}$ prior to reperfusion in mice [27]. 
In humans, a 4-h intravenous infusion of GTN protects the heart against ischaemia during coronary angioplasty conducted $24 \mathrm{~h}$ later, as evidenced by reduced ST-segment elevation, ischaemic dysfunction, and pain [24]. However, how well these clinical endpoints relate to experimentally used endpoints of myocardial damage caused by ischaemia and reperfusion injury, and the precise relationship between GTN and preconditioning are not entirely clear [18]. Several studies of STEMI patients from the thrombolytic era, as well as a more recent study, have not found evidence for infarct size reduction after nitrate or nitrite infusion [2]. Interestingly, in a recent study, intracoronary but not i.v. infusion of nitrites reduced infarct size in STEMI patients with completely occluded arteries at admission [21, 33], in whom reperfusion injury might be expected to be a significant factor. GTN is sometimes administered to patients undergoing surgical coronary revascularization, at the discretion of the anaesthesiologist. However, when comparing patients who do not receive GTN to those who receive $0.042 \pm 0.024 \mathrm{mg} /$ $\mathrm{kg}$ GTN, no evidence for a reduction peri-procedural injury was found, as determined by cTnI release [23]. Surprisingly, the simple, practical, and cost-effective method of inducing acute cardioprotection by simply applying a GTN patch prior to reperfusion had not been previously investigated.

Nitrates and nitric oxide can protect the heart via multiple possible mechanisms, but this appears to be independent from their vasodilatory effects [5]. Nitric oxide can directly nitrosate proteins and also activate a pathway involving nitric oxide-sensitive guanylyl cyclase and cGMP-dependent protein kinase type I (PKGI) in cardiomyocytes [6, 9]. Recently, these have been shown to activate cardioprotection via large-conductance, $\mathrm{Ca}^{2+}$-dependent potassium (BK) channels $[8,17]$.

The GTN patch used here was designed to deliver $5 \mathrm{mg} /$ day, so the $1 / 8$ patch we used is expected to deliver $0.026 \mathrm{mg} / \mathrm{h}$. However, we did not perform a dose-response experiment to establish the optimal dose of GTN. Basal levels of plasma nitrite vary considerably and decrease with increasing numbers of cardiovascular risk factors [22]. Plasma nitrates are also affected by dietary nitrates. Dietary inorganic nitrate ingestion or supplementation causes a dosedependent elevation in plasma nitrite concentration with a consequent decrease in blood pressure in healthy volunteers. A meta-analysis found a significant association of the dose of inorganic nitrate supplementation with decline in systolic blood pressure, with a factor of $-0.12 \mathrm{mmHg} / 1.0 \mathrm{mmol}$ nitrate $(P<0.05)$ [34]. Although it would be of interest to test for an association between infarct size and plasma nitrite, this was not possible in our study since the quantity of blood necessary for the nitrite assay made it impossible to perform infarction using the same mice.

When using this approach, it is important to be aware that excessive nitrate concentrations are potentially damaging, and in addition to nitrate tolerance, can cause nitro-oxidative stress. Endothelial dysfunction, formation of DNA adducts, and even apoptotic death of vascular cells has been seen when $10-50 \mathrm{mg} / \mathrm{kg} / \mathrm{day}$ nitrate was administered to rats for 3 days [26]. Furthermore, prolonged exposure to GTN can induce tolerance. For example, 7 days of transdermal GTN exposure abolished pacing-induced preconditioning in conscious rabbits [35] and abrogated the effectiveness of remote ischaemic conditioning in rat myocardium and human volunteers [10]. Interestingly, however, direct myocardial protection with glyceryl trinitrate (GTN) may be preserved in the state of vascular nitrate tolerance [5].

Clinical studies are required to establish the potential efficacy of using the transdermal GTN patch in the setting of patients who are experiencing an STEMI. These will necessitate careful determination of the appropriate dose and timing of administration. However, its simplicity and rapidity (easily applied in an ambulance or cardiac catheterization laboratory), and low cost (potentially relevant to low-income countries), make it attractive for further investigation.

Funding NIHR Biomedical Research Council (SD), British Heart Foundation PG/15/52/31598 (SD, DH) and the The Hatter Foundation.

\section{Compliance with ethical standards}

Conflict of interest The authors declare that they have no competing interests.

Open Access This article is distributed under the terms of the Creative Commons Attribution 4.0 International License (http://creativeco mmons.org/licenses/by/4.0/), which permits unrestricted use, distribution, and reproduction in any medium, provided you give appropriate credit to the original author(s) and the source, provide a link to the Creative Commons license, and indicate if changes were made.

\section{References}

1. Baker JE, Su J, Fu X, Hsu A, Gross GJ, Tweddell JS, Hogg N (2007) Nitrite confers protection against myocardial infarction: role of xanthine oxidoreductase, NADPH oxidase and K(ATP) channels. J Mol Cell Cardiol 43:437-444. https://doi. org/10.1016/j.yjmcc.2007.07.057

2. Bice JS, Jones BR, Chamberlain GR, Baxter GF (2016) Nitric oxide treatments as adjuncts to reperfusion in acute myocardial infarction: a systematic review of experimental and clinical studies. Basic Res Cardiol 111:23. https://doi.org/10.1007/s0039 5-016-0540-y

3. Bromage DI, Pickard JM, Rossello X, Ziff OJ, Burke N, Yellon DM, Davidson SM (2017) Remote ischaemic conditioning reduces infarct size in animal in vivo models of ischaemia-reperfusion injury: a systematic review and meta-analysis. Cardiovasc Res 113:288-297. https://doi.org/10.1093/cvr/cvw219

4. Bush PA, Gonzalez NE, Griscavage JM, Ignarro LJ (1992) Nitric oxide synthase from cerebellum catalyzes the formation of 
equimolar quantities of nitric oxide and citrulline from L-arginine. Biochem Biophys Res Commun 185:960-966

5. Csont T, Ferdinandy P (2005) Cardioprotective effects of glyceryl trinitrate: beyond vascular nitrate tolerance. Pharmacol Ther 105:57-68. https://doi.org/10.1016/j.pharmthera.2004.10.001

6. Davidson SM, Yellon DM (2018) Cardioprotection-is NO the answer? A renewed look at nitric oxide signalling in cardiomyocytes. Cardiovasc Res. https://doi.org/10.1093/cvr/cvy073 (in press)

7. Duranski MR, Greer JJ, Dejam A, Jaganmohan S, Hogg N, Langston W, Patel RP, Yet SF, Wang X, Kevil CG, Gladwin MT, Lefer DJ (2005) Cytoprotective effects of nitrite during in vivo ischemia-reperfusion of the heart and liver. J Clin Investig 115:1232-1240. https://doi.org/10.1172/JCI22493

8. Frankenreiter S, Bednarczyk P, Kniess A, Bork NI, Straubinger J, Koprowski P, Wrzosek A, Mohr E, Logan A, Murphy MP, Gawaz M, Krieg T, Szewczyk A, Nikolaev VO, Ruth P, Lukowski R (2017) cGMP-elevating compounds and ischemic conditioning provide cardioprotection against ischemia and reperfusion injury via cardiomyocyte-specific BK channels. Circulation 136:23372355. https://doi.org/10.1161/CIRCULATIONAHA.117.028723

9. Frankenreiter S, Groneberg D, Kuret A, Krieg T, Ruth P, Friebe A, Lukowski R (2018) Cardioprotection by ischemic postconditioning and cGMP-elevating agents involves cardiomyocyte nitric oxide-sensitive guanylyl cyclase. Cardiovasc Res. https:// doi.org/10.1093/cvr/cvy039

10. Hauerslev M, Mork SR, Pryds K, Contractor H, Hansen J, Jespersen NR, Johnsen J, Heusch G, Kleinbongard P, Kharbanda R, Botker HE, Schmidt MR (2018) Influence of long-term treatment with glyceryl trinitrate on remote ischemic conditioning. Am J Physiol Heart Circ Physiol. https://doi.org/10.1152/ajpheart.00114 .2018

11. Hausenloy DJ, Barrabes JA, Botker HE, Davidson SM, Di Lisa F, Downey J, Engstrom T, Ferdinandy P, Carbrera-Fuentes HA, Heusch G, Ibanez B, Iliodromitis EK, Inserte J, Jennings R, Kalia N, Kharbanda R, Lecour S, Marber M, Miura T, Ovize M, PerezPinzon MA, Piper HM, Przyklenk K, Schmidt MR, Redington A, Ruiz-Meana M, Vilahur G, Vinten-Johansen J, Yellon DM, Garcia-Dorado D (2016) Ischaemic conditioning and targeting reperfusion injury: a 30 year voyage of discovery. Basic Res Cardiol 111:70. https://doi.org/10.1007/s00395-016-0588-8

12. Hausenloy DJ, Baxter G, Bell R, Botker HE, Davidson SM, Downey J, Heusch G, Kitakaze M, Lecour S, Mentzer R, Mocanu MM, Ovize M, Schulz R, Shannon R, Walker M, Walkinshaw G, Yellon DM (2010) Translating novel strategies for cardioprotection: the Hatter workshop recommendations. Basic Res Cardiol 105:677-686. https://doi.org/10.1007/s00395-010-0121-4

13. Hausenloy DJ, Garcia-Dorado D, Botker HE, Davidson SM, Downey J, Engel FB, Jennings R, Lecour S, Leor J, Madonna R, Ovize M, Perrino C, Prunier F, Schulz R, Sluijter JPG, Van Laake LW, Vinten-Johansen J, Yellon DM, Ytrehus K, Heusch G, Ferdinandy P (2017) Novel targets and future strategies for acute cardioprotection: position paper of the European Society of Cardiology Working Group on cellular biology of the heart. Cardiovasc Res 113:564-585. https://doi.org/10.1093/cvr/cvx049

14. Hausenloy DJ, Kharbanda R, Rahbek Schmidt M, Moller UK, Ravkilde J, Okkels Jensen L, Engstrom T, Garcia Ruiz JM, Radovanovic N, Christensen EF, Sorensen HT, Ramlall M, Bulluck H, Evans R, Nicholas J, Knight R, Clayton T, Yellon DM, Botker HE (2015) Effect of remote ischaemic conditioning on clinical outcomes in patients presenting with an ST-segment elevation myocardial infarction undergoing primary percutaneous coronary intervention. Eur Heart J 36:1846-1848. https://doi.org/10.1093/ eurheartj/ehv249
15. Hausenloy DJ, Yellon DM (2016) Ischaemic conditioning and reperfusion injury. Nat Rev Cardiol 13:193-209. https://doi. org/10.1038/nrcardio.2016.5

16. Hendgen-Cotta UB, Merx MW, Shiva S, Schmitz J, Becher S, Klare JP, Steinhoff HJ, Goedecke A, Schrader J, Gladwin MT, Kelm M, Rassaf T (2008) Nitrite reductase activity of myoglobin regulates respiration and cellular viability in myocardial ischemiareperfusion injury. Proc Natl Acad Sci USA 105:10256-10261. https://doi.org/10.1073/pnas.0801336105

17. Heusch $\mathrm{G}$ (2017) Cardioprotection is alive but remains enigmatic: the nitric oxide-protein kinases-mitochondria signaling axis. Circulation 136:2356-2358. https://doi.org/10.1161/CIRCULATIO NAHA. 117.031978

18. Heusch G (2001) Nitroglycerin and delayed preconditioning in humans: yet another new mechanism for an old drug? Circulation 103:2876-2878

19. Hill M, Takano H, Tang XL, Kodani E, Shirk G, Bolli R (2001) Nitroglycerin induces late preconditioning against myocardial infarction in conscious rabbits despite development of nitrate tolerance. Circulation 104:694-699. https://doi.org/10.1161/hc320 1.092218

20. Ignarro LJ, Fukuto JM, Griscavage JM, Rogers NE, Byrns RE (1993) Oxidation of nitric oxide in aqueous solution to nitrite but not nitrate: comparison with enzymatically formed nitric oxide from L-arginine. Proc Natl Acad Sci USA 90:8103-8107. https:// doi.org/10.1073/pnas.90.17.8103

21. Jones DA, Pellaton C, Velmurugan S, Rathod KS, Andiapen M, Antoniou S, van Eijl S, Webb AJ, Westwood MA, Parmar MK, Mathur A, Ahluwalia A (2015) Randomized phase 2 trial of intracoronary nitrite during acute myocardial infarction. Circ Res 116:437-447. https://doi.org/10.1161/CIRCRESAHA.116.30508 2

22. Kleinbongard P, Dejam A, Lauer T, Jax T, Kerber S, Gharini P, Balzer J, Zotz RB, Scharf RE, Willers R, Schechter AN, Feelisch M, Kelm M (2006) Plasma nitrite concentrations reflect the degree of endothelial dysfunction in humans. Free Radic Biol Med 40:295-302. https://doi.org/10.1016/j.freeradbiomed.2005.08.025

23. Kleinbongard P, Thielmann M, Jakob H, Peters J, Heusch G, Kottenberg E (2013) Nitroglycerin does not interfere with protection by remote ischemic preconditioning in patients with surgical coronary revascularization under isoflurane anesthesia. Cardiovasc Drugs Ther 27:359-361. https://doi.org/10.1007/s1055 7-013-6451-3

24. Leesar MA, Stoddard MF, Dawn B, Jasti VG, Masden R, Bolli R (2001) Delayed preconditioning-mimetic action of nitroglycerin in patients undergoing coronary angioplasty. Circulation 103:2935-2941

25. Liu X, Huang Y, Pokreisz P, Vermeersch P, Marsboom G, Swinnen M, Verbeken E, Santos J, Pellens M, Gillijns H, Van de Werf F, Bloch KD, Janssens S (2007) Nitric oxide inhalation improves microvascular flow and decreases infarction size after myocardial ischemia and reperfusion. J Am Coll Cardiol 50:808-817. https:// doi.org/10.1016/j.jacc.2007.04.069

26. Mikhed Y, Fahrer J, Oelze M, Kroller-Schon S, Steven S, Welschof P, Zinssius E, Stamm P, Kashani F, Roohani S, Kress JM, Ullmann E, Tran LP, Schulz E, Epe B, Kaina B, Munzel T, Daiber A (2016) Nitroglycerin induces DNA damage and vascular cell death in the setting of nitrate tolerance. Basic Res Cardiol 111:52. https://doi.org/10.1007/s00395-016-0571-4

27. Nagasaka Y, Fernandez BO, Garcia-Saura MF, Petersen B, Ichinose F, Bloch KD, Feelisch M, Zapol WM (2008) Brief periods of nitric oxide inhalation protect against myocardial ischemiareperfusion injury. Anesthesiology 109:675-682. https://doi. org/10.1097/ALN.0b013e318186316e

28. Pickard JM, Botker HE, Crimi G, Davidson B, Davidson SM, Dutka D, Ferdinandy P, Ganske R, Garcia-Dorado D, Giricz Z, 
Gourine AV, Heusch G, Kharbanda R, Kleinbongard P, MacAllister R, McIntyre C, Meybohm P, Prunier F, Redington A, Robertson NJ, Suleiman MS, Vanezis A, Walsh S, Yellon DM, Hausenloy DJ (2015) Remote ischemic conditioning: from experimental observation to clinical application: report from the 8th Biennial Hatter Cardiovascular Institute Workshop. Basic Res Cardiol 110:453. https://doi.org/10.1007/s00395-014-0453-6

29. Rassaf T, Totzeck M, Hendgen-Cotta UB, Shiva S, Heusch G, Kelm M (2014) Circulating nitrite contributes to cardioprotection by remote ischemic preconditioning. Circ Res 114:1601-1610. https://doi.org/10.1161/CIRCRESAHA.114.303822

30. Salloum FN, Takenoshita Y, Ockaili RA, Daoud VP, Chou E, Yoshida K, Kukreja RC (2007) Sildenafil and vardenafil but not nitroglycerin limit myocardial infarction through opening of mitochondrial K(ATP) channels when administered at reperfusion following ischemia in rabbits. J Mol Cell Cardiol 42:453-458. https ://doi.org/10.1016/j.yjmcc.2006.10.015

31. Schulz R, Kelm M, Heusch G (2004) Nitric oxide in myocardial ischemia/reperfusion injury. Cardiovasc Res 61:402-413. https:// doi.org/10.1016/j.cardiores.2003.09.019

32. Shiva S, Sack MN, Greer JJ, Duranski M, Ringwood LA, Burwell L, Wang X, MacArthur PH, Shoja A, Raghavachari N, Calvert JW, Brookes PS, Lefer DJ, Gladwin MT (2007) Nitrite augments tolerance to ischemia/reperfusion injury via the modulation of mitochondrial electron transfer. J Exp Med 204:2089-2102. https ://doi.org/10.1084/jem.20070198
33. Siddiqi N, Neil C, Bruce M, MacLennan G, Cotton S, Papadopoulou S, Feelisch M, Bunce N, Lim PO, Hildick-Smith D, Horowitz J, Madhani M, Boon N, Dawson D, Kaski JC, Frenneaux M, Investigators N (2014) Intravenous sodium nitrite in acute ST-elevation myocardial infarction: a randomized controlled trial (NIAMI). Eur Heart J 35:1255-1262. https://doi.org/10.1093/ eurheartj/ehu096

34. Siervo M, Lara J, Ogbonmwan I, Mathers JC (2013) Inorganic nitrate and beetroot juice supplementation reduces blood pressure in adults: a systematic review and meta-analysis. J Nutr 143:818826. https://doi.org/10.3945/jn.112.170233

35. Szilvassy Z, Ferdinandy P, Nagy I, Jakab I, Koltai M (1997) The effect of continuous versus intermittent treatment with transdermal nitroglycerin on pacing-induced preconditioning in conscious rabbits. Br J Pharmacol 121:491-496. https://doi.org/10.1038/ sj.bjp. 0701163

36. Totzeck M, Hendgen-Cotta UB, Rassaf T (2017) Nitrite-nitric oxide signaling and cardioprotection. Adv Exp Med Biol 982:335-346. https://doi.org/10.1007/978-3-319-55330-6_18

37. Tripathi Y, Hegde BM, Raghuveer CV (1997) Effect of superoxide dismutase and acidified sodium nitrite on infarct size following ischemia and reperfusion in dogs. Indian J Physiol Pharmacol 41:248-256 